\title{
CONTINUOUS NSW HEALTH SURVEY: QUARTERLY REPORT ON HEALTH STATUS, HEALTH BEHAVIOURS, AND RISK FACTORS
}

\author{
Katie Irvine and Margo Eyeson-Annan \\ Centre for Epidemiology and Research \\ NSW Department of Health
}

This is the second of a series of quarterly reports on the surveillance of the health status, health behaviours, and risk factors of the people of NSW, which will be produced from the Continuous NSW Health Survey. The first quarterly report covered the period March to December 2002. Ten indicators have been selected for inclusion in the quarterly report. These have been chosen either because they are of ongoing interest or because seasonal variation is possible (Figure 1). The Continuous NSW Health Survey is conducted by the Centre for Epidemiology and Research, through the Department of Health's computer-assisted telephone interviewing facility. The data described in this report are based on the respondents described in Table 1. Although prevalence estimates only are shown in the graphs, 95 per cent confidence intervals have been calculated and these are available on request from the NSW Health Survey Program.

\section{SELF-RATED HEALTH}

Self-rated health is believed to principally reflect physical problems and, to a lesser extent, health behaviours and mental health problems. Longitudinal studies have shown that self-rated health is a strong and independent predictor of subsequent illness and premature death. ${ }^{1}$ In 2003, 80.8 per cent of NSW residents aged 16 years and over reported their health as being either 'excellent', 'very good', or 'good'. There was no significant difference in self-rated health between males (81.9 per cent) and female (79.8 per cent).

\section{MOST PEOPLE CAN BE TRUSTED}

Trust involves a willingness to take risks in a social context. This willingness is based on a confidence that others will respond as expected and will act in mutually supportive ways — or at least will not attend harm. In 2003, 69.6 per cent of NSW residents either 'agreed' or 'strongly agreed' that most people can be trusted. A significantly higher proportion of males (71.5 per cent) than females (67.9 per cent) agreed that most people can be trusted. For females, the proportion was significantly higher in 2003 than in 2002 (62.0 per cent).

\section{ALCOHOL RISK DRINKING}

Risk-drinking behaviour includes one or more of the following: consuming alcohol every day; consuming on average more than four (if male) or two (if female) standard drinks; or consuming more than six (if male) or four (if female) standard drinks on any one occasion or day. ${ }^{2}$ In 2003, 35.7 per cent of residents reported undertaking riskdrinking behaviours. A significantly higher proportion of males (41.3 per cent) than females (30.3 per cent) reported risk-drinking behaviour.

\section{CURRENT SMOKER}

Current smoking includes 'daily' and 'occasional' smoking. In 2003, 22.5 per cent of respondents reported current smoking. A significantly higher proportion of males (25.0 per cent) than females (20.0 per cent) reported current smoking.

\section{RECOMMENDED VEGETABLE INTAKE}

The recommended daily intake of vegetables is four serves for females over 12 years of age, and for males 12-18 years of age and over 60 years of age. Five serves are

\section{TABLE 1}

RESPONDENTS AGED 16 YEARS AND OVER BY COLLECTION QUARTER

\begin{tabular}{|c|c|c|c|}
\hline Quarter & Males & Females & Persons \\
\hline February-March 2002 & 386 & 609 & 995 \\
\hline April-June 2002 & 1444 & 1993 & 3437 \\
\hline July-September 2002 & 1768 & 2345 & 4113 \\
\hline October-December 2002 & 1645 & 2266 & 3911 \\
\hline February-March 2003 * & 1245 & 1903 & 3148 \\
\hline April-June 2003 & 1574 & 2191 & 3765 \\
\hline July-September 2003 & 1674 & 2317 & 3991 \\
\hline October-December 2003 & 803 & 1189 & 1992 \\
\hline
\end{tabular}




\section{FIGURE 1}

QUARTERLY REPORT OF SELECTED INDICATORS, CONTINUOUS NSW HEALTH SURVEY, MARCH 2002 TO DECEMBER 2003
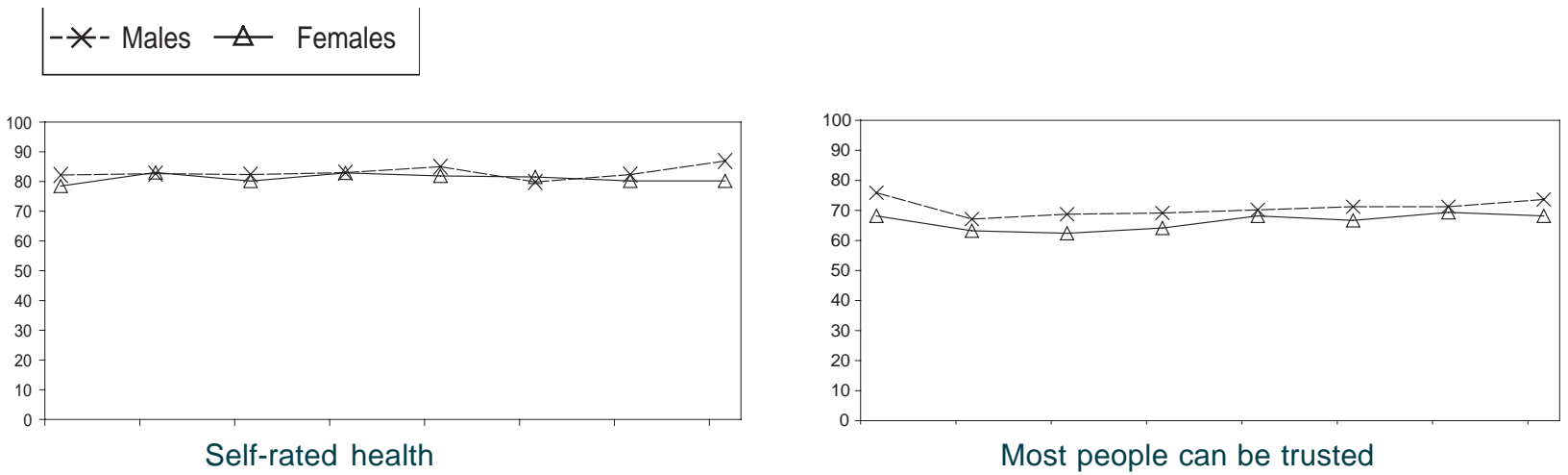

Most people can be trusted

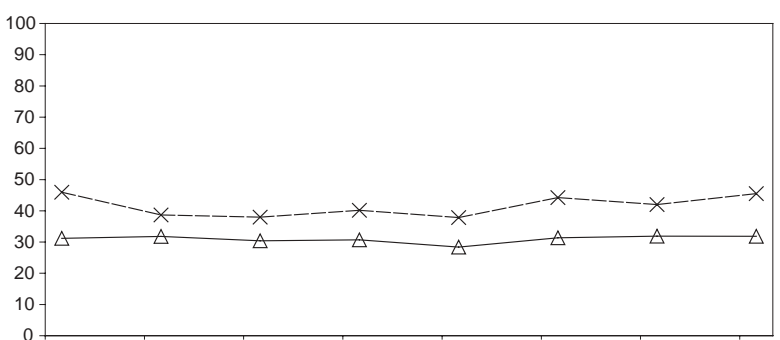

Alcohol risk drinking

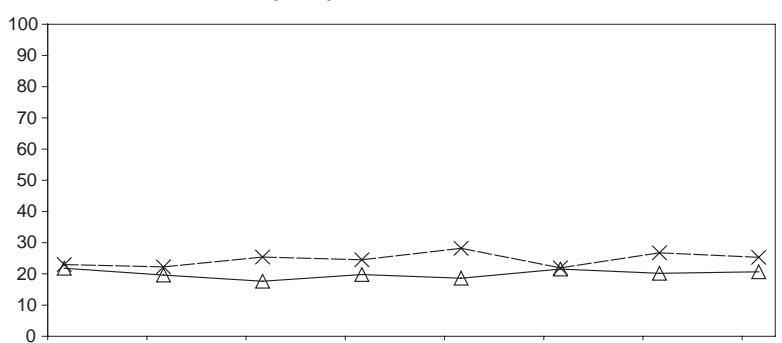

Current smoker
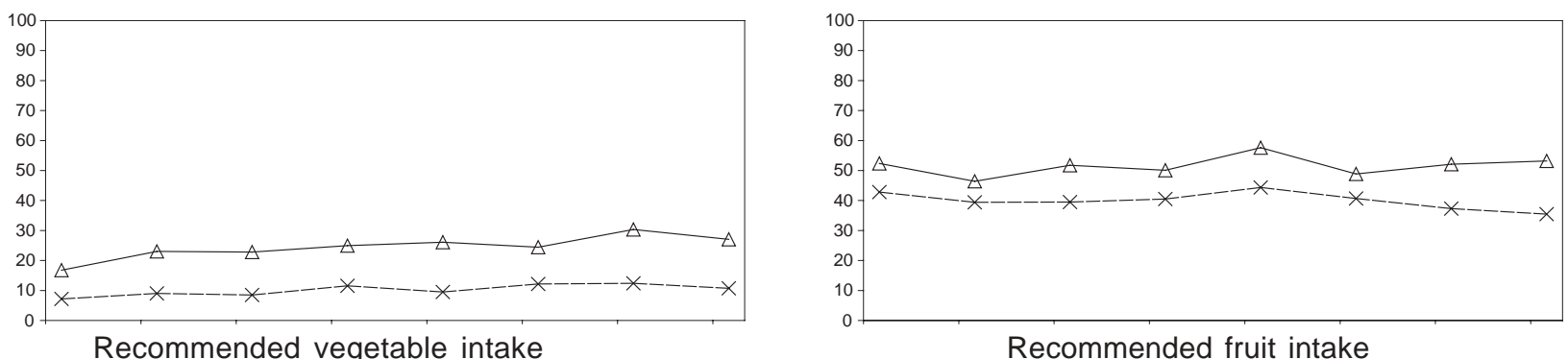

Recommended fruit intake

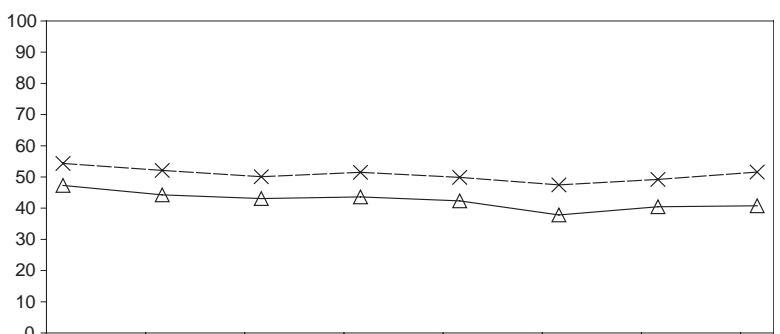

Adequate physical activity

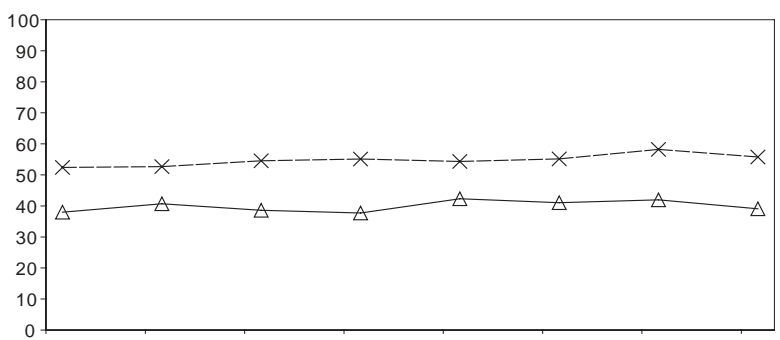

Overweight or obese
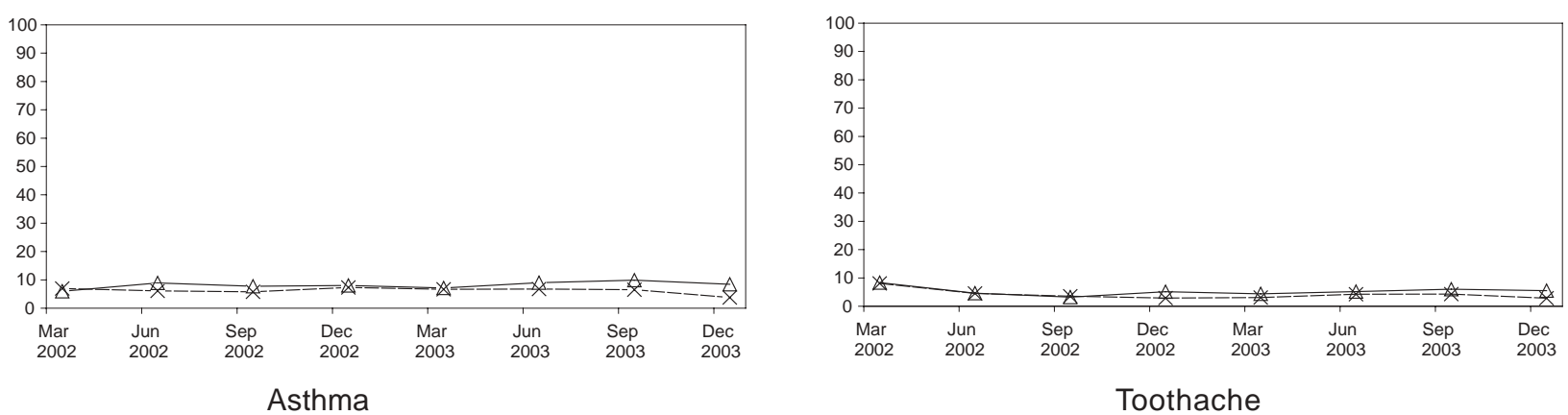

Source: NSW Health Survey Program, Centre for Epidemiology and Research, NSW Department of Health. 
recommended for males aged 19-60 years. ${ }^{3}$ In 2003, 19.3 per cent of people consumed the recommended quantities of vegetables. A significantly higher proportion of females (26.7 per cent) than males (11.8 per cent) ate the recommended amount of vegetables. This is significantly higher than the proportion of females ( 22.9 per cent) and males (9.2 per cent) that consumed recommended quantities in 2002.

\section{RECOMMENDED FRUIT INTAKE}

The recommended daily fruit intake is three serves for people 12-18 years of age and two serves for people 19 years of age and over. ${ }^{3}$ In 2003, 45.8 per cent of NSW residents consumed the recommended amount of fruit. A significantly greater proportion of females (52.4 per cent) than males (39.0 per cent) ate the recommended quantities of fruit.

\section{ADEQUATE PHYSICAL ACTIVITY}

To maintain health it is currently recommended that moderate intensity exercise is carried out on all or most days of the week for at least 30 minutes per day. 'Adequate' physical activity is defined as a total of 150 minutes per week over five separate occasions. ${ }^{4}$ In 2003, 45.0 per cent of people undertook adequate physical activity. Significantly more males (49.5 per cent) than females (40.6 per cent) reported undertaking adequate physical activity.

\section{OVERWEIGHT OR OBESE}

Self-reported height and weight were used to estimate body mass index (BMI), which was used to classify respondents into body weight categories. A BMI of 25 to less than 30 is classified as overweight, and a BMI of equal to or greater than 30 as obese. In 2003, 48.3 per cent of people were classified as overweight or obese. Significantly more males (55.6 per cent) than females (41.0 per cent) were overweight or obese.

\section{ASTHMA}

In 2003, 11.0 per cent of people reported having current asthma. A significantly greater proportion of females (12.7 per cent) than males ( 9.2 per cent) reported having asthma. In 2003, 7.4 per cent of people reported having asthma symptoms or seeking management for asthma in the last four weeks.

\section{TOOTHACHE}

In 2003, 4.8 per cent of people had a toothache 'often' or 'very often' in the last four weeks. There was no significant difference in toothache rates between males ( 4.2 per cent) and females (5.4 per cent).

\section{REFERENCES}

1. Krause NM and Jay GM. What do global self-rated health items measure? Medical Care 1994; 32: 930-942.

2. National Health and Medical Research Council. Australian Alcohol Guidelines: Health Risks and Benefits. Canberra, NHMRC, 2001.

3. National Health and Medical Research Council. Dietary Guidelines for Australian Adults. Canberra: NHMRC, 2003.

4. Commonwealth Department of Health and Aged Care. National Physical Activity Guidelines for Australians. Canberra: Commonwealth Department of Health and Aged Care, 2002. 佂

\section{CONTESTING FREEDOMS IN HEALTHCARE:THE 10TH CONFERENCE OFTHE AUSTRALASIAN BIOETHICS ASSOCIATION, NOVEMBER 2004}

The 10th Conference of the Australasian Bioethics Association, incorporating the 9th Conference of the Australian Institute of Health Law and Ethics, will be held on 12-14 November 2004 at the University of NSW. The theme of the Conference is Contesting Freedoms in Healthcare: Policy, Practice, and Ethics. The Conference program includes orations and public lectures by:

- Beth Wilson: 'Does shaming, naming and blaming improve the quality of our health services? Adversarial versus conciliatory approaches to investigating health complaints';

- Miles Little: 'Expressing freedom and taking liberties: The paradoxes of aberrant science';

- Max Charlesworth: 'Ethics and the Bioethics Project';

- Deborah Diniz: 'Reproductive rights and academic freedom: A view from the South'.

Further information about the 10th Conference of the Australasian Bioethics Association, Contesting Freedoms in Healthcare can be obtained from the website www.australasian-bioethics.org.au/conference.

The 7th World Congress of Bioethics is being held in parallel, on 9-12 November. Further information about that Congress can be found at www.bioethicsworldcongress.com. 